\title{
Impact Analysis of Oil Pollution using Change Detection Techniques in Kuwait
}

\author{
Shafiullah G. \\ Department of Earth and Environmental Sciences, Khaldiya, Kuwait University, Kuwait
}

\begin{abstract}
The present study reveals impact of oil pollution in the environment of Kuwait. The change detection techniques were applied to analyze the changes. The present study has been analyzed using digital satellite data such as 1990, 1993, 1999 and 2006. Based on hierarchy the data were applied various image processing technique like, principal component analysis, change detection analysis between 1993 to 1999 and 1999 to 2006, filtering techniques, classification, accuracy assessment and post classification methods. The results are revealed that the majority (90\%) of the oil pollution occurred in the southern part of Kuwait.
\end{abstract}

Keywords - Remote Sensing, Principle Component, Change Detection, Post Classification.

\section{INTRODUCTION}

Land use land covers are one of the important elements of global environment change processes (Dickinson 1995; Hall et al. 1995). Change detection of land cover has great potential in remote sensing application. Land cover may be foundout and differentiated from each other by their unique spectral responses patterns. Several studies demonstrated the effectiveness of using satellite-derived data (Sabins 1997; Abou El-Magd and Tanton 2003; Cardille and Foley2003; Lobo et al. 2004; Musaoglu et al. 2005) in detecting landscape change (LCC) over time,

Change detection is the process of identifying in the state of an object by observing it at different times (Singh 1989). In general, change detection involves the application of multitemporal datasets for the quantitativeanalysisof the temporal changes in the phenomenon or the state of an object. Remote sensing data are the primary source extensively used for change detection in recent decades and have made a great impact on land use / land cover management (Yeh and Li 1999;Ji et al. 2001; Yangand Lo 2002; Shen and Kheoruenromne 2003; Rogan and Chen 2004).

During the last two decades, many new change detection techniques are used. These are affected by spatial, spectral, thematic and temporal constraints; the selection of a suitable method for a task is not easy (Lu et al. 2004). They can be broadly divided into either pre-classifications or post-classifications change detection methods (Nelson 1983;Pilon et al. 1988;singh 1989). Most changedetection techniques are in the spectral change identification category, such as image differencing, image ratioing, vegetation index difference, principal component analysis (PCA), change vector analysis (CVA) and post classification analysis. All of these methods (except subtraction method) involve some type of transformation designed to normalize between the raw images (Lunetta and Elvidge 1998).

PCA is a mathematical technique for reducing the dimension of a data set into few components (Jackson 1983). Processing multidimensional remote sensing data, the PCA is highly powerful technique used to identify the patterns in the data, and the components are most informative.PCA is an orthogonal linear transformation that re-expresses multivariate data. It extracts the greatest variance in a set of data on the first axis (called the first principal component). The second greatest variance is the second component and so on. PCA is used as a main rule in the change detection technique in remote sensing (Jensen 1986; Fung and LeDrew 1987).

In post-classification change detection, different dates of two images are independently classified and labeled. The area of change is then extracted through the direct comparison of the classification results (Colwell and Weber 1981, Howarth and Wickware 1981). The advantage of post-classification change detection is that it by- passes the difficulties in change detection associated with the analysis of images acquired at different times of years of by different it sensors. The high sensitivity isbased on the accuracy of individual classification is the major disadvantage of the post-classification. The aim of this study is to find out the quantitative changes of oil polluted land cover changes (LCC) in Burgan areausing PC first components of different dates (1993, 1999 and 2006).

\section{STUDY AREA}

Kuwait is a part of the Arabian Gulf composed of the desert, Kuwait Bay\& part of the northwestern Arabian Gulf. It extends between latitudes $28^{\circ} 30^{\prime} \mathrm{N}$ and $30^{\circ} 05^{\prime} \mathrm{N}$ and longitudes $46^{\circ} 3^{\prime} \mathrm{E}$ and $48^{\circ} 35^{\prime} \mathrm{E}$ (Fig. 1.1B). It is topographically low-relief desert, the maximum relief is approximately $270 \mathrm{~m}$ in Jal Al-Zor, and the wadi Al-Batin is the only valley in this region. The land surface slopes gradually northeast wards with an average gradient of approximately $2 \mathrm{~m} / \mathrm{km}$, whereas there are many irregular 
slopes which are due the temporary sand dunes. Dust and dust storms, locally known as 'toze' occur in the Kuwait region throughout the year but are more frequent during the spring and summer months (i.e. March to August)
(Kwarten and Chaver1998). Due to dust storms, sand encroachment is one of the main environmental problems in Kuwait.

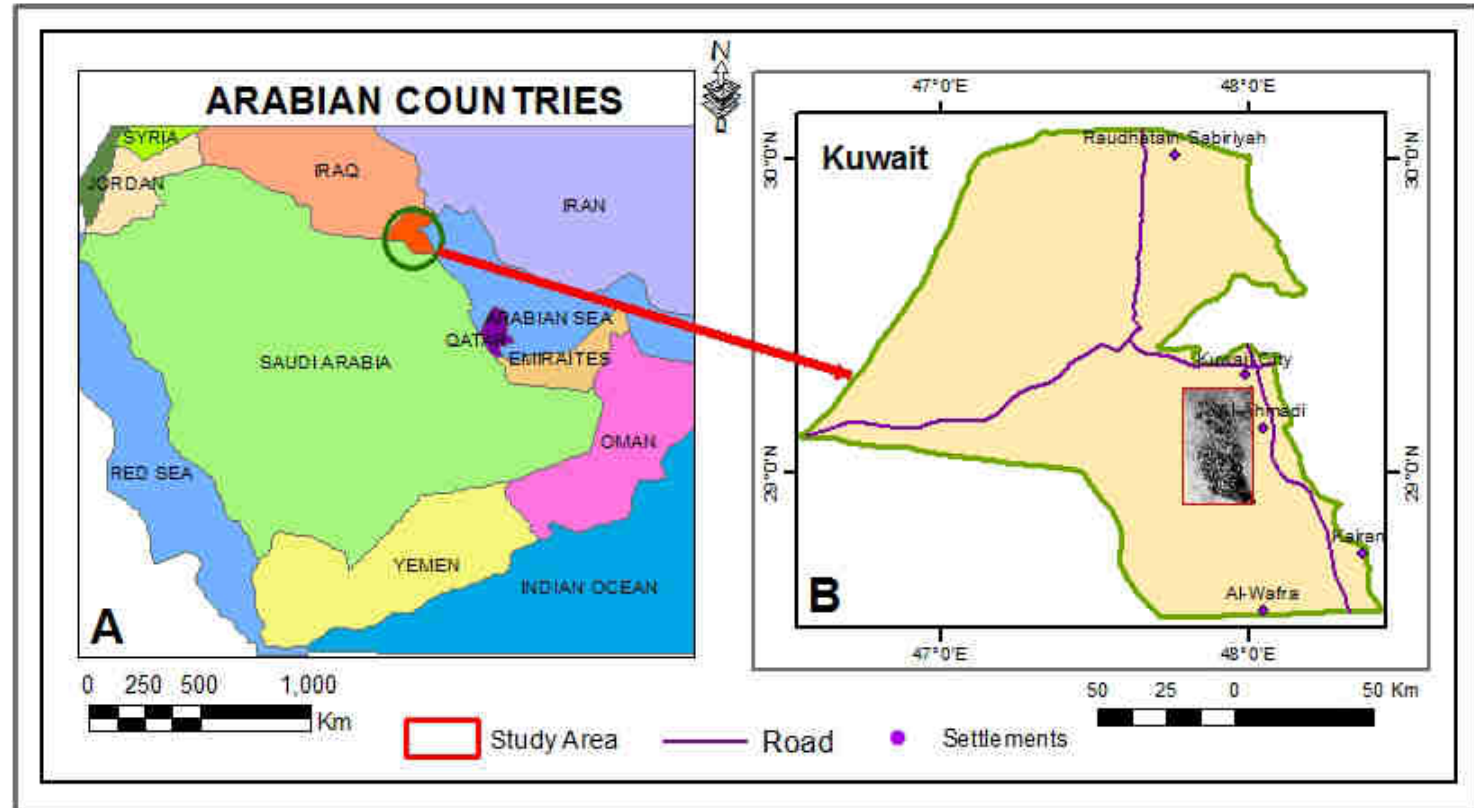

Fig. 1: A Location map of Kuwait; Fig.1B Location map of the study area

Kuwait's main economical resource is oil. The largest oil resource comes from the Burgan oil field, which is a sub-surface dome with oil impregnated in Miocene sandstone and highly permeable middle Cretaceous layers. During Gulf war,Kuwaitoil wellheads wereblown and oilspread on ground (Fig. 2A). The burning wells produced large amounts of toxic gases and dark smoke(Fig.2B), which were potentially hazardous to human health,living animals and vegetation growth. Due to the hydrostatic pressure,the damaged wells were gushing oil (Fig.2C), forced oil out to the surface. The gushed oil formed as streams in hot sand. It is estimated that more than one billion barrels of crude oil was lost during this war.

When all the wells were capped and the last oil fire was extinguished, approximately 300 oil lakes of various sizes had been formed in the oil fields (Kwarteng 1998). The free-flowing crude oil accumulated and formed networks of oil rivers, lakes and oil pools (Fig. 2D) which contained moreover 25 to 40 million barrels of oil.
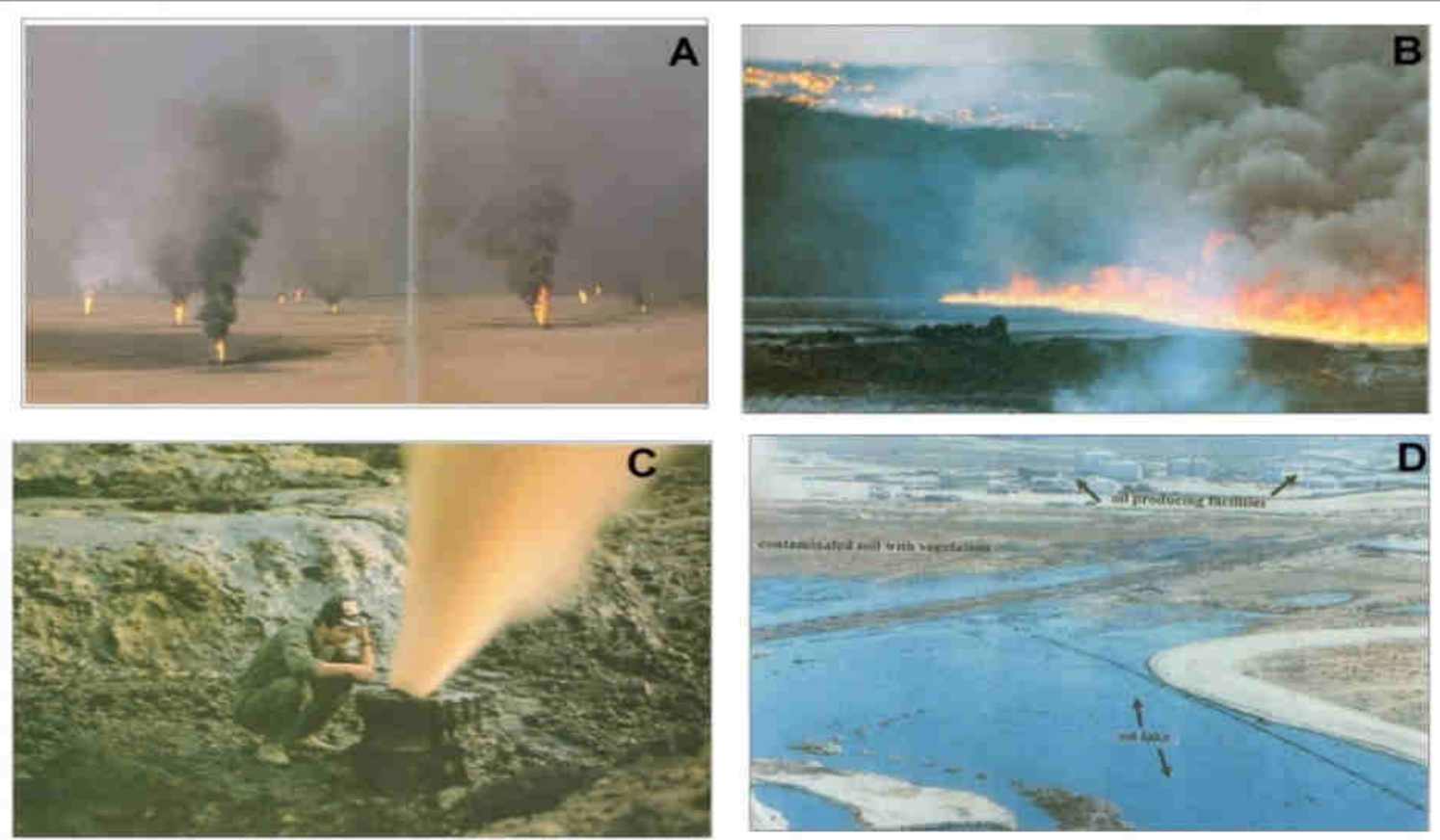

Fig. 2 A \& B: Oil wells are firing and dark smoke; C: A head broken well gushing oil, D: Oil lakes, Tarmat and contaminated surface at the Burgan oil field. 
The remaining non recoverable oil infiltrated into the ground or dried up forming tarmats. Additionally, more than $1722 \mathrm{~km}^{2}$, representing 10 percent of the total land surface of Kuwait, was covered by oil mist and soot (Kwarteng 1999). Tarmats varied in thickness from a few millimeters to about two centimeters. The soot eventually turned the soil underneath black. Some of the oil lakes were concealed by a vaneer of sand and could not be observed from the surface (Kwarteng 1998).

Some of the oil migrated to new locations as a result of occasional strong rain-storms and flash floods. Contaminated soil, inhibited vegetation growth, produced health risks to humans and animals (Kwarteng 1999), making the event one of the worst environmental disasters in history (Al-Ajmi et al. 1994; El-Baz et al. 1994; Kwarteng 1998). The main objective of this study was to identify the oil polluted land cover surface (LC) and its temporal changes (LCC)using multi-temporal and multisensor remote sensing satellite data.

\section{MATERIALS AND METHODS}

Oil pollution of this region continued for more than one decade. Remote sensing was used in several projects and studies to characterize this pollution and offer invaluable information on the status of the oil-polluted surfaces (AlAjmi et al. 1994; El-Baz et al. 1994; Kwarteng and AlAjmi 1997; Koch and El-Baz 1998; Kwarteng 1998).The majority $(90 \%)$ of the oil pollution occurred in the southern part of Kuwait. The detailed investigation of temporal changes in pollution evaluation of southern area, a set of TM and $\mathrm{ETM}^{+}$images of path 165 and row 40 of multi-temporal images of 1990, 1993, 1999 and 2006 digital data were used. Table-1lists the acquired data for day time cloudless images having 30 meter resolution. All data were chosen in winderbetween March to April times.

Table1: Digital Satellite Data Used in the Study

\begin{tabular}{|c|c|c|c|c|}
\hline Date & Sensor & Path & Row & Resolution $\left(\mathbf{m}^{2}\right)$ \\
\hline $28 / 02 / 1990$ & TM & 165 & 40 & 30 \\
\hline $28 / 02 / 1993$ & TM & 165 & 40 & 30 \\
\hline $09 / 03 / 1999$ & TM & 165 & 40 & 30 \\
\hline $04 / 02 / 2006$ & ETM+ & 165 & 40 & 30 \\
\hline
\end{tabular}

\section{Data Settings and Pre-Processing}

The pre-processes of the chosen imageswere done by the geometric correction which is the process of warping the image to fit a planimetric grid or map projection. This process is crucial in remote sensing particularly in change detection. By geometrical rectification, a given pixel remains at the same geographic location in all the images utilized in the study. The sequence of digital image processing is shown in Fig.3.

\section{Pre-Processing of \\ Image 1990 \\ Image 1993 \\ Image 1999 \\ Image2006}

Fig.3: Hierarchy Chart of Image Processing

All the 6 bands (visible bands Red 1, Green 2, \& Blue 3; Infra-Red 4andMid Infra-Red 5 \& 7) of 1990 date images (except band 6 , the thermal band) were stacked. Band 7 (Mid Infra-Red band) is denoted as band 6 in this study. The 1990 TM image was used as the master image from which all the other images were rectified through imageto-image registration to the Universal Transverse Mercator Projection (UTM/ zone 39N; WGS 84) using a first-order polynomial transform. For each image registration, at least 20 prominent well-distributed ground control points (GCP) were chosen and a nearest neighbor re-sampling method was adopted. The root mean square error (RMSE) ranged from 0.4-0.5 pixel for each registered image. Ninety percent of oil production of this country comes from the Great Burgan oil field located in southeast of this country (Kwarteng and Al-Ajmi 1997), and this was subset for further processing.

The images comprised both of high surface brightness (light, white) and low surface brightness (dark, black) areas.In images with two distinct light and dark areas, the use of normal contrast stretching techniques, such as linear stretching and edge enhancement, to simultaneously enhance the local details in both regions do not yield satisfactory results (Chavez 1984). Such conditions are typically observed in arid environment, where the spectral reflections are dominated by high values from the bright soil and vegetation (Kwarteng and Chavez 1998).

\section{Principal Component Analysis (PCA)}

In multi-band remote sensing images, the bands are the original variable. Some of the original bands may be highly correlated; such bands could be combined into new, less correlated Eigen images by PCA. Computationally, three steps are involved in the principal component transformation (Eklundh and Singh 1993). The first is the calculation of a covariance or correlation matrix using the input data sets. Second is the calculation of Eigen values and Eigen vectors, and the third is the calculation of principal components.

$$
C=\frac{\sum_{j=1}^{n}\left(X_{j}-M\right)\left(X_{j}-M\right)^{T}}{n-1}
$$

Where, $X$ and $M$ are the multiband image individual and mean pixel value vectors, respectively, and $\mathrm{n}$ is the number of pixels. 
Table.2: Eigen Values and Percentage of variances of 6 bands in 1990, 1993, 1999 and 2006.

\begin{tabular}{|l|c|c|c|c|c|c|c|c|}
\hline & \multicolumn{2}{|c|}{1990} & \multicolumn{2}{c|}{1993} & \multicolumn{2}{c|}{1999} & \multicolumn{2}{c|}{2006} \\
\hline Comp's & Eigenvalue & Percentage & Eigenvalue & Percentage & Eigenvalue & Percentage & Eigenvalue & Percentage \\
\hline Comp1 & 1281.82 & 95.26 & 2813.08 & 97.17 & 3174.02 & 95.21 & 1672.86 & 94.83 \\
\hline Comp2 & 37.64 & 2.80 & 57.32 & 1.98 & 122.34 & 3.67 & 57.74 & 3.27 \\
\hline Comp3 & 16.40 & 1.22 & 10.78 & 0.37 & 19.61 & 0.59 & 24.07 & 1.36 \\
\hline Comp4 & 5.15 & 0.38 & 7.82 & 0.27 & 11.13 & 0.33 & 5.63 & 0.32 \\
\hline Comp5 & 3.73 & 0.28 & 4.59 & 0.16 & 5.74 & 0.17 & 2.63 & 0.15 \\
\hline Comp6 & 0.80 & 0.06 & 1.37 & 0.05 & 0.95 & 0.03 & 1.08 & 0.06 \\
\hline Total & 1345.56 & 100.00 & 2894.97 & 100.00 & 3333.78 & 100.00 & 1764.00 & 100.00 \\
\hline
\end{tabular}

All six bands of subset Burgan images are chosen for PCA analysis. The statistical details of 6 variance/ covariance matrices, 6 band correlation matrix and 6 eigenvector valueshave been obtained through this analysis report. The eigenvalues and their percentagesfor 1990, 1993, 1999 and 2006 images are given in Table 2. As per the PC processes, the first component has high Eigen value which is $97.17 \%$ of 1993 , showing high degree of correlated with all their bands. The least one is 2006 , which is $94.83 \%$ of eigenvalues. Only $5 \%$ of values are scattered over all 6 images of each set of data.

\section{Change Detection}

Thismethod is widely used and consists of subtracting registered images acquired at different times, pixel by pixel and band by band.Direct subtraction of one image from other byspatially registered of multi temporal images.

$$
D X_{i j}^{k}=X_{i j}^{k}\left(t_{2}\right)-X_{i j}^{k}\left(t_{1}\right)
$$

Where, $D X_{i j}^{k}$ is the difference between pixel value $\mathrm{x}$ located at row and column, for band, between acquisition date1 $\left(\mathrm{t}_{1}\right)$ and date2 $\left(\mathrm{t}_{2}\right)$. No changes between times results in pixel values 0 , but if changes occurred these values should be positive or negative. The challenge of this technique is to identify threshold values of change and no change in the resulting images. The image differencing method is usually applied to single bands but can be also applied to processes data such as multi date vegetation indices or principal components. Subtracting the second image date from the corresponding image of the first date after performing PCA separately (Abdullah and Lalit Kumar 2013; Deng el at. 2008). The first PC component of 1993, 1999 and 2006 of the study area were done by image differencing among which the 1993 images are highly polluted whereas the 2006 is least polluted. The resulted images are the difference between 1999 with 1993 and 2006 with 1999.

\section{Classification}

The placement of the threshold level is the most critical part of the image differencing change detection method. The type of change occurring should be determined when placing the threshold level.This type of change must be noted in order to adequately place the threshold without much trial and error to study about the equal amount of changes occurring in both the gain and loss of digital value.Compared to the accuracy of the final change classification, the threshold level is very important and may be the determining factor.In order to remove fraction pixel changes and get clear classification, the change differencing images were filtered using $3 X 3$ filter algorithm. The standard deviation threshold value may perform the best because it uses equal threshold values on each side of the mean (Robb, D. and Russell, G., 1998).

Many different types of classification and total polluted area shows pervious study of this area based on the different types of processing and methods. On 1992 TM images, 300 oil lakes of various sizes covers an area of more than $49 \mathrm{~km} 2$ and then reduced into $35.45 \mathrm{~km} 2$ in 1995. In the same way, in 1992 using TM data, the total oil polluted area was $1722 \mathrm{~km}^{2}$ and became $98 \mathrm{~km}^{2}$ only when observed in March 1995 in the following classification such as oil lakes, tarmats, oil mist and thick soot/black oil using TM (Kwarteng 1998). Oil lakes, tarmats, black soil varied according to thickness and the amount of vegetation and sand/ dust cover, In the southern part, dark soils had about the same digital number values as some oil lakes (Kwarteng 1998).

The bulk of the oil-contaminated soil occurs in the dry oil lakes areas $(70 \%)$ and oil lake areas $(24 \%)$. Oily soil is the dominant type of contaminated soil layer.

1. Oil spreading over the land surface and penetrating the soil to varying depth,

2. Aerial fallout from oil spray and combustion products from oil fire; and

3. Formation of oil lakes on the land surface.

Area estimates of oil lakes in the Greater Al-Burgan area range from $14.07 \mathrm{~km}^{2}$ (Al-Ajmi et al. 1994) to $35.4 \mathrm{~km}^{2}$ (Kwarteng 1998) and $24.14 \mathrm{~km}^{2}$ (Kwarteng 1999) soot, tarmats, oily soil, liquid oil and clean soil (Samira Omar et al. 2006). Oil lakes, dry oil lake, tarmats, contaminated soil clean soil. The final classification is as follows:

1. Oil Lakes (OL): Consists of liquid or semi Liquid oil over the Soil (In 1993 TMimage, southern part of Burgan area wascovered by black soot over the tarmats showing the same $\mathrm{DN}$ values). 
2. Dark Oily Soil (DOS): (Oil less and Soil more) mixture of oil and soil with waxy or the nextstage of oil lakes becomestar mats; it is considered as Dry oil lakes.

3. Tarmats (Tar): Consists of dried oilthat became tarmats or oil lakes dried and had fresh and covered on it.

4. Black Soil (BS):Soil covered with soot or oil mist over the soil showing black in color

5. Contaminated Soil (Cont.Soil):The oil spray over the soil or weathered tarmats became a black soil which included the vegetation (1990 and 2006 images).

6. Polluted Soil (Poll. Soil): Manmade pollution during war or man used area.

7. White Soil: Clean Sand or White Soil.

\section{Accuracy Assessment}

The imperative role of remote sensing classification and change-detection applications is played by the accuracy assessment which is very important for understanding the detected change results and employing these results for land management. The application of an error matrix that can be used as a starting point for a series of descriptive and analytical statistical analysis is the most common method for accuracy assessment. The overall accuracy, producer's accuracy (the number of samples correctly classified for a given column divided by total for that column) (Lillesand and kiefer 1994; Story and Congalton 1986; Aronoff 1982b), user's accuracy (the number of samples correctly classified for a given row divided by total for that row), and kappa coefficient (Congalton 1991;Congalton and Green 1999;Foody 2002). The related assessment elements include to correctly performingclassification accuracy assessment, it is necessary to compare two source of information:

1. The remote sensing derived classification map and

2. What we call reference test information (which may in fact contain error).

The error matrix commonly summarizes the relationship between these two sets of information. Two differencing change detection imagesand each one from Pc1 of 1993,1999 and 2006 were collected randomly from training datasets(region of interest (ROI) files) to assess the accuracy of classification maps (Chen Xiuwen el at. 1999).Overall accuracy and Kappa Coefficient of 1993, 1999, 2006 and the differential images between 19931999 and 1999- 2006 are listed in the table 3. Overall accuracy values of these 5 images ranges from $93.8 \%$ to 99.7\%. Image 1993 shows $93.3 \%$ and its kappa values 0.9256 whereas, classified image 1999 gives $99.7 \%$ which kappa value is 0.99960 .

Table-3Accuracy Assessment of overall Accuracy and Kappa Values

\begin{tabular}{|l|l|l|}
\hline & Overall Accuracy & Kappa \\
\hline
\end{tabular}

\begin{tabular}{|c|c|c|c|}
\hline & Pixels & Percentage & Coefficient \\
\hline 1993 & $15549 / 16574$ & 93.8156 & 0.9256 \\
\hline 1999 & $59841 / 60007$ & 99.7234 & 0.9960 \\
\hline 2006 & $11020 / 11349$ & 97.1011 & 0.9649 \\
\hline $\begin{array}{c}1993- \\
1999\end{array}$ & $87204 / 91347$ & 95.4645 & 0.9359 \\
\hline $\begin{array}{c}1999- \\
2006\end{array}$ & $112199 / 113452$ & 98.8956 & 0.9832 \\
\hline
\end{tabular}

\section{Post Classification}

Post-classification comparison method is widely used, provide more details about the object that are selected and provide more information about change trends. Two images acquired at different times are independently classified and then compared. Ideally, similar thematic classes are produced for each classification. Changes between the two dates can be visualized using a change matrix, for both dates, the number of pixels in each class. Image classification applies to post-classification change detection approaches and can be performed using standard deviation from mean method. The standard deviation from mean technique was applied for the correct classification of oil polluted areas.Prior to labeling, the classes representing variations of the same LC category (e.g contaminated soil with other contaminated soil) were merged in order to reduce the number of classes. The classification procedure resulted with LC maps and statistics for three different dates. The LC maps that show spatial distribution of 7 classes for the study images were given in fig. 4 and the area coverage of the LC categories were summarized in table 4.The classification of three components (image differencing between (1999-1993), (2006-1999) and the first component of complaint PC had been classified.

\section{RESULTS AND DISCUSSION}

The total study area is 984554 pixels which is $30 \mathrm{X} 30$ meter resolution; approximately $886 \mathrm{Km}^{2}$ areas covered mainly Burgan oil field.The study area has 984555 pixels which is about $886.10 \mathrm{~km}^{2}$ shownin the figure1B.This is the main oil resource field in Kuwait and was highly polluted during Gulf war. Many previous studies either direct survey or using satellite images estimated area of pollution in this area. Different methods of processing give different result but change detection process using PC1 to calculate area by the post classification seems to be good result.

\section{Land Cover Oil Pollution changes using PCA Analyses}

The combining of 6 bands in to PCA analysis gives the PC component. The first component of 1990, 1993, 1999 and 2006 give almost 95\% Eigen value than other components. The PC first component of 4 year images and their $5^{\text {th }}$ components images are displayed in figure 4 . 
In 1990, even though it is an oil field and oil production was going on, there was not much oil pollution in this region. The northern part of oil field (Fig. 4-A1) had just few dark patches which were oil leaked during production. The dark area in the east part is Ahmadi settlements. The PC5 component of Ahmadi area (A2) was changed into light color and few patches on oil leakage area are well distinguished.

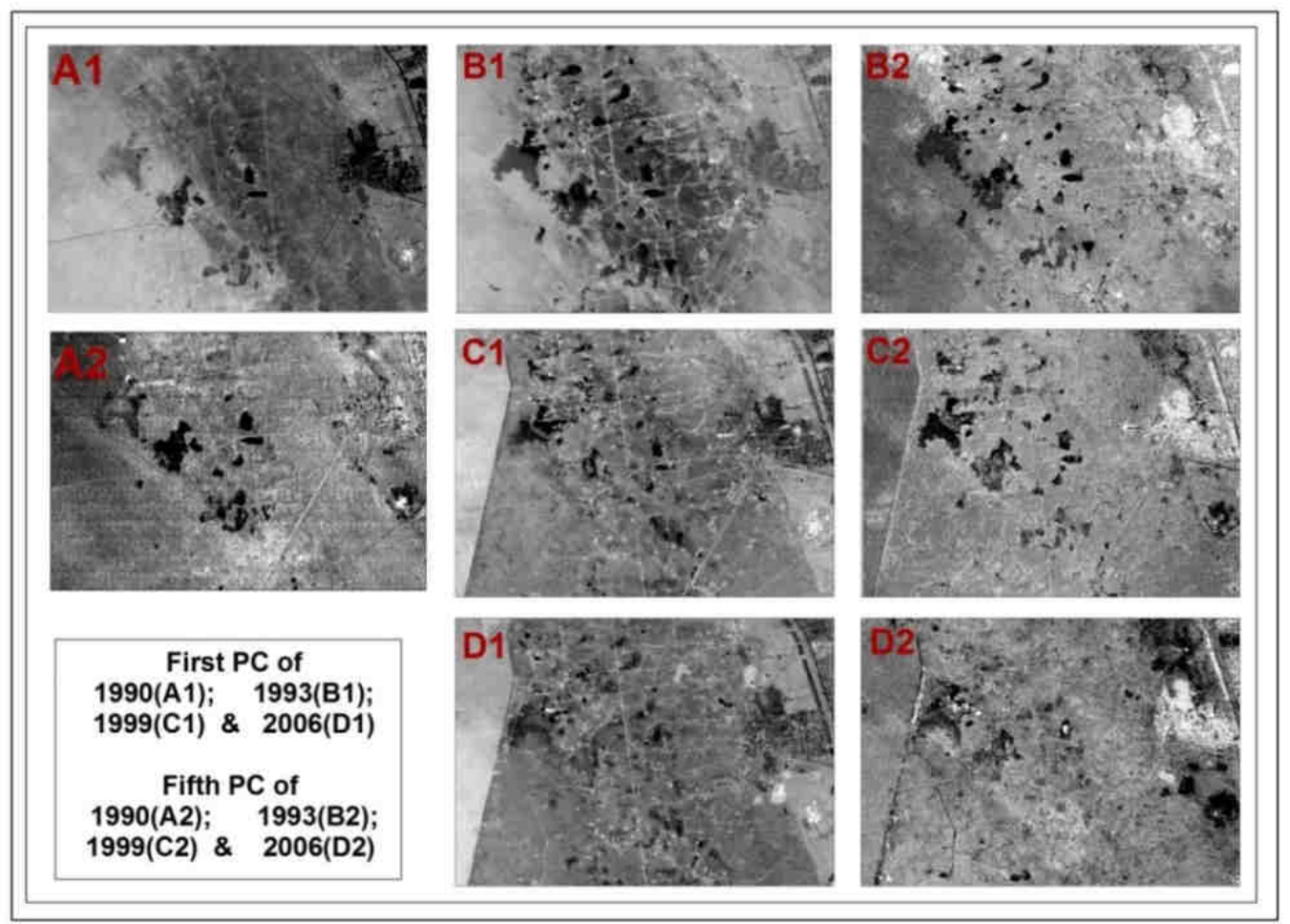

Fig.4: Principal Component Analysis Images from Northern Part of Study Area

The first component of 1993, 1999 and 2006 and their $5^{\text {th }}$ component are displayed in Figure4 B1, B2; C1, C2; and D1, D2 respectively. The 1993 Pc1 (B1) image shows more oil lakes and tarmats with black shadow overall image and it was clear with Pc5 of 1993 (B2) image. Whereas, (C1 \& C2) in 1999 there were reduction in this level and very few patches of oil lakes are shown in 2006 in Pc5 (D1 \& D2) component.

\section{Temporal Changesof oil pollution by Classification}

First, the PC first component images filtered with low pass $3 \mathrm{X} 3$ filter algorithm to sharpen the edges of each class and classified into 13 classes using standard deviation from mean classification. The area has two end members where oil lakes are dark in tone whereas desert is pure white in color. These 13 classes are further merged according to surrounding classes to become 7 classes. All four yearimages (first PC of four years 1990, 1993, 1999 and 2006 images) were classified in the same method. Table3lists the details of each class pixel values and its square kilometers of seven classes. The figures5 shows the seven classes of 4 years; the red color (Oil Lakes) almost nil in 1990 became more in 1993again became nil in 2006.

Table.4: Number of Pixels and area of classified images

\begin{tabular}{|l|c|c|c|c|c|c|c|c|}
\hline & \multicolumn{2}{|c|}{1990} & \multicolumn{2}{c|}{1993} & \multicolumn{2}{c|}{1999} & \multicolumn{2}{c|}{2006} \\
\hline Classes & Pixels & $\mathrm{Km}^{2}$ & Pixels & $\mathrm{Km}^{2}$ & Pixels & $\mathrm{Km}^{2}$ & Pixels & $\mathrm{Km}^{2}$ \\
\hline Oil Lakes & 336 & 0.30 & 30931 & 27.84 & 4714 & 4.24 & 3282 & 2.95 \\
\hline Dark Oily Soil & 775 & 0.70 & 115111 & 103.60 & 6357 & 5.72 & 3287 & 2.96 \\
\hline Tarmats & 4497 & 4.05 & 201951 & 181.76 & 65252 & 58.73 & 21793 & 19.61 \\
\hline Black Soil & 21737 & 19.56 & 274044 & 246.64 & 187936 & 169.14 & 157932 & 142.14 \\
\hline Cont. Soil & 189989 & 170.99 & 294240 & 264.82 & 364691 & 328.22 & 442304 & 398.07 \\
\hline Polluted Soil & 382080 & 343.87 & 67928 & 61.14 & 225035 & 202.53 & 188586 & 169.73 \\
\hline White Soil & 385141 & 346.63 & 350 & 0.32 & 130570 & 117.51 & 167371 & 150.63 \\
\hline Total & 984555 & 886.10 & 984555 & 886.10 & 984555 & 886.10 & 984555 & 886.10 \\
\hline
\end{tabular}


Figure 6, the bar diagram shows the change in difference of value of area in each class at that time. The temporal changes in 1990 were very less in both oil lakes and dark oily soil but the tarmats shows $4 \mathrm{~km}^{2}$ which were formed during drilling.

Contaminated soil in this period was only vegetation.

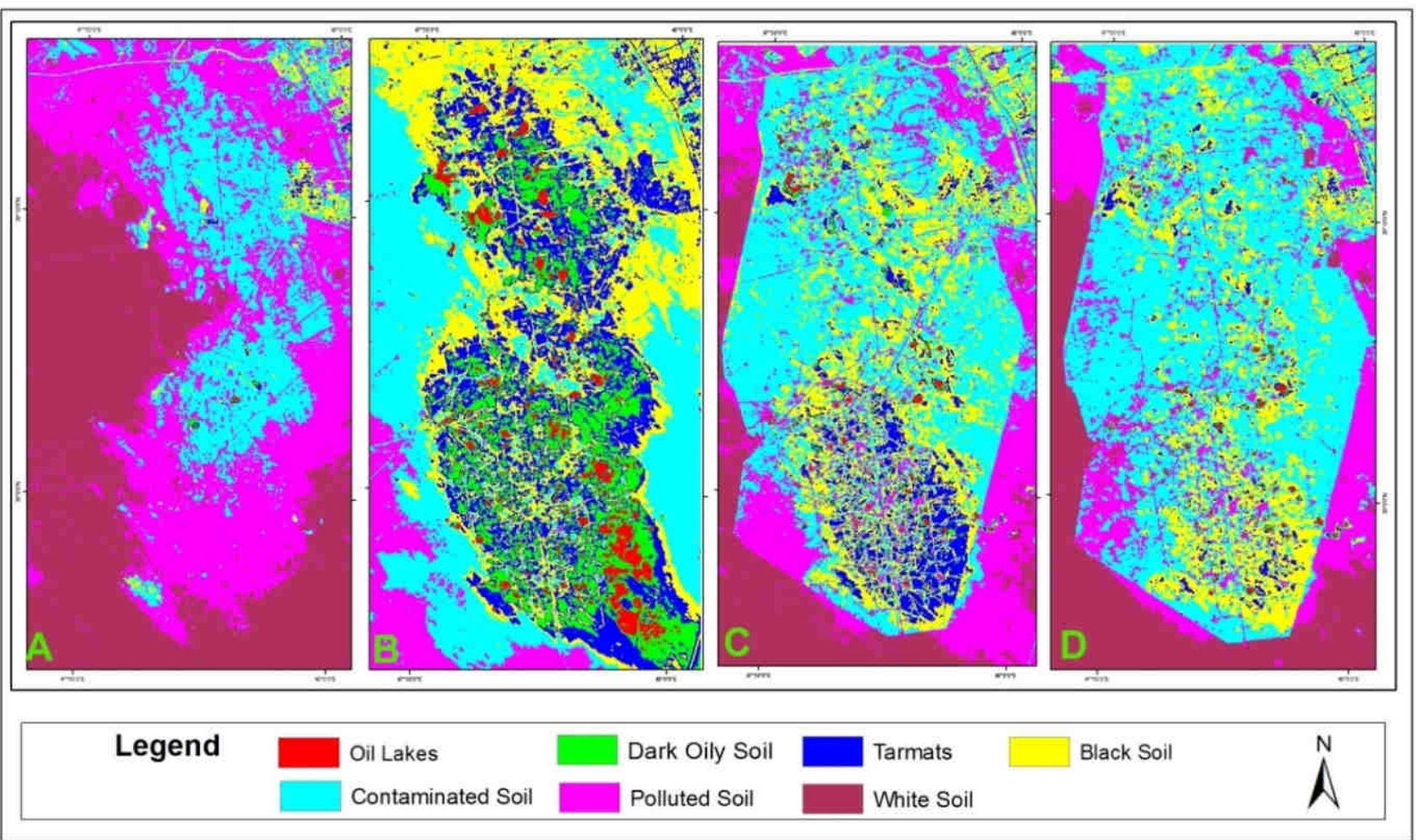

Fig.5: Seven classes images of 1990, 1993, 1999 and 2006 showing A, B, C \& D respectively

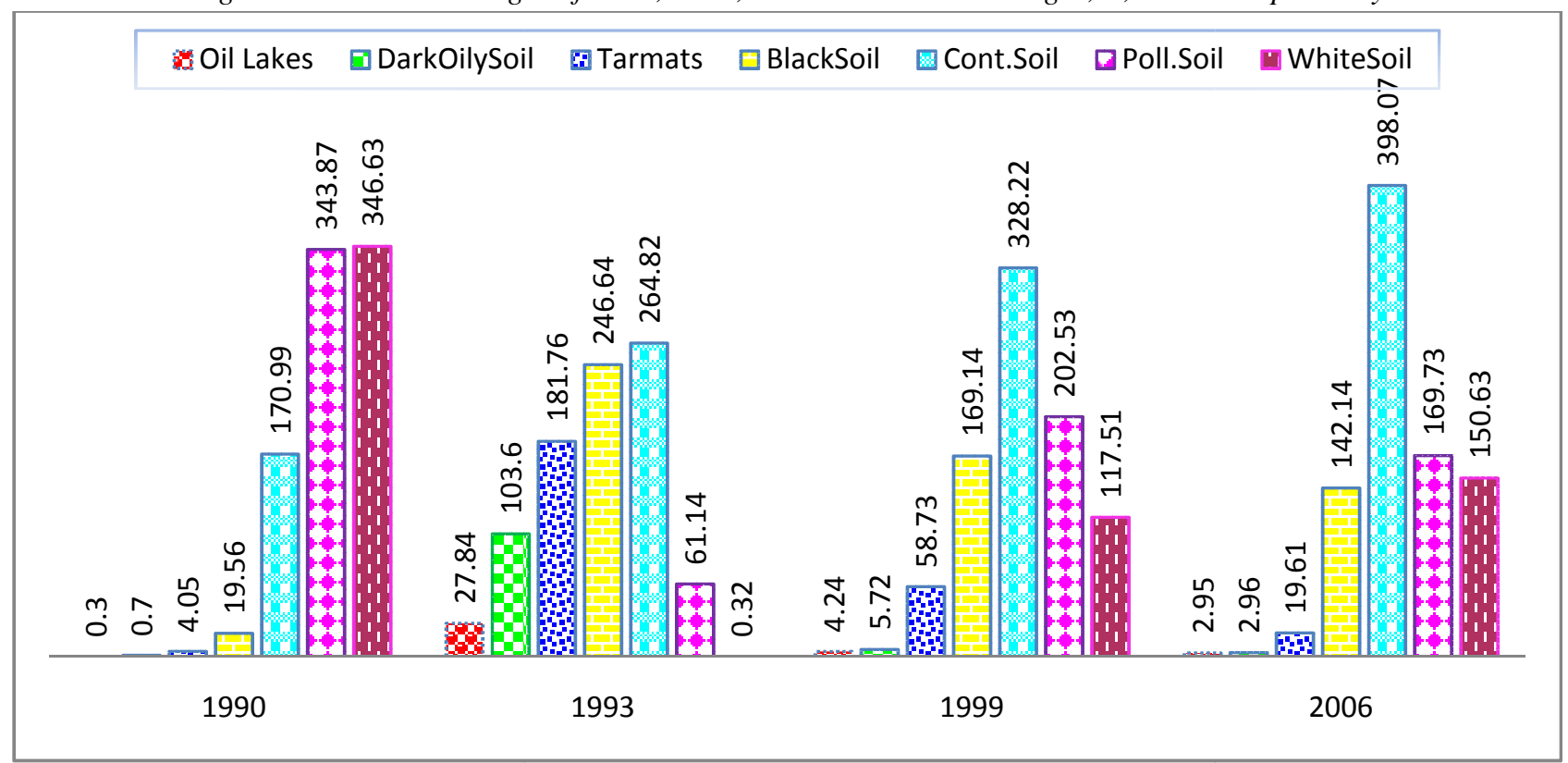

Fig.6: Bar diagram showing 7 classes of each year and their Square Kilometers

Polluted area here was manmade pollution due to increasing in oil field production work had been done. In 1993, the same area had a distinct change because of gulf war. The oil lakes are $27 \mathrm{~km}^{2}$ followed by $103 \mathrm{~km}^{2}$ dark oily soil and $181 \mathrm{~km}^{2}$ tarmats. In 1990 , vegetation was done in the contaminated soil in 1993, because in 1990, vegetation was burned during gulf war and oil was sprayed very long distance (Fig.2C). The polluted class is manmade pollution while fighting to stop oil wells burning were used many vehicles and water. In the subsequent period (1999), vegetation was more, that is, total Burgan area was fenced increasing vegetation in this area.

Compare to 1999 \& 2006 oil lakes, Dark oily soil, tarmats and black soil were reduced gradually. Area covered in these classes in 2006 was not gulf war pollution; these 
were formed due to oil production. The contaminated soil showing increased because of vegetation increasing. Whereas soil was increased from $117 \mathrm{~km}^{2}$ to $150 \mathrm{~km}^{2}$ in 2006 conforming that the oil pollution during Gulf War was totally reduced and increase desert soil. The total area of normal soil was reduced where compare to 1990 indicating development of oil field.

\section{Land Cover Oil Pollution ChangesDetection using} image differencing

The PC first component of 1993, 1999 and 2006 were subtracted to know the difference of change of oil pollution. The image difference between 1999-1993 and 2006-1999 are shown figure7 A \& B. The data 1999 was used as common image for both image differencing to identify exact pollution in 1993 and 2006. Images are processed further by $3 \times 3$ filter to sharpenthe edge of each class and avoid the confusion. The filter images are classified into 7 classes using by standard deviation from the mean algorithm method.

Total number of pixels and its square areas of each class of two differentiated images are given in the table 4. The oil lakes were decreasing three times more than 19931999images. The same patterns of reduction are also followed in dark oily soil, tarmats and black soils. Tarmats was $101.74 \mathrm{~km}^{2}$ became $15.13 \mathrm{~km}^{2}$. The same way black soil reduced from $242.26 \mathrm{~km}^{2}$ to $92.26 \mathrm{~km}^{2}$ because of black soil formed by the soot deposition was removed by heavy wind.

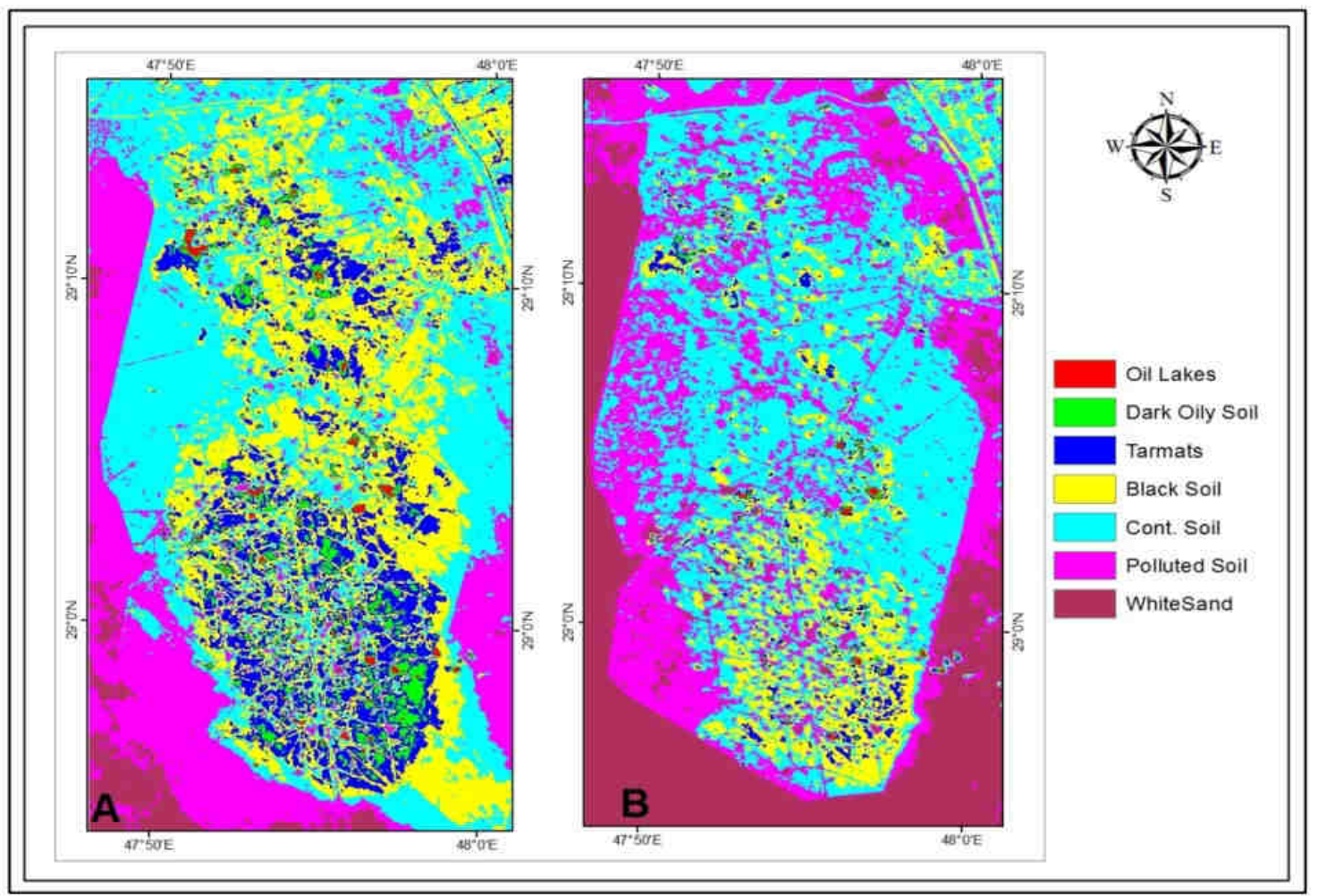

Fig.7: A-1999 \& 1993 and B- 2006 \& 1999 differentiated Classified images

Table.5: Total Number of Pixels and $\mathrm{Km}^{2}$ of 7 classes the differentiated temporal images

\begin{tabular}{|l|c|c|c|c|}
\hline & \multicolumn{2}{|c|}{$1993-1999$} & \multicolumn{2}{c|}{$1999-2006$} \\
\hline Classes & Pixels & $\mathrm{km}^{2}$ & Pixels & $\mathrm{km}^{2}$ \\
\hline Oil Lakes & 4837 & 4.35 & 1330 & 1.20 \\
\hline Dark Oily Soil & 24711 & 22.24 & 2757 & 2.48 \\
\hline Tarmats & 113047 & 101.74 & 16812 & 15.13 \\
\hline Black Soil & 269177 & 242.26 & 102516 & 92.26 \\
\hline Contaminated Soil & 342914 & 308.62 & 365409 & 328.87 \\
\hline Polluted Soil & 192836 & 173.55 & 265134 & 238.62 \\
\hline White Soil & 37033 & 33.33 & 230597 & 207.54 \\
\hline Total & 984555 & 886.10 & 984555 & 886.10 \\
\hline
\end{tabular}


On the other hand, the remaining classes such as contaminated soil, polluted soil and white soil were increased. The contaminated soil formed due to spray of oil on the soil which should be reduced in the next period but increased because of DN vales of contaminated soil and vegetation are almost same by maintaining of the Burgan areas. The white soil which is desert increasing tremendously in 1999-2006 differencing image indicating the recovery of oil pollution into desert.
Quantitative Changes of Land Cover Oil pollution using Post Classification

Temporal changes of each class in each year had been calculated to monitoring the minute changes of oil pollution. Land cover changes between first difference (PC1-1993 \& PC1-1999)image into second difference (PC1-1999\& PC1-2006)image of post classification are given in the table-6. Significant land cover and land cover changes have been clearly identified around study area.

Table.6: Post classification of the difference between PC1-1993 \& PC1-1999 (Initial) and PC1-1999 \& PC1-2006 (Final) change detection images values in square kilometer.

\begin{tabular}{|c|c|c|c|c|c|c|c|c|c|}
\hline & & \multicolumn{8}{|c|}{ 1993-99 Change detection Seven Classes Image } \\
\hline & Classification & $\begin{array}{c}\text { Oil } \\
\text { Lakes }\end{array}$ & $\begin{array}{c}\text { Dark Oily } \\
\text { Soil }\end{array}$ & Tar & $\begin{array}{c}\text { Black } \\
\text { Soil }\end{array}$ & $\begin{array}{l}\text { Cont. } \\
\text { Soil }\end{array}$ & $\begin{array}{c}\text { Poll. } \\
\text { Soil }\end{array}$ & $\begin{array}{c}\text { White } \\
\text { Soil }\end{array}$ & Total \\
\hline \multirow{8}{*}{ 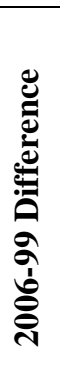 } & Oil Lakes & 0.94 & 0.22 & 0.04 & & & & & 1.20 \\
\hline & DarkOilySoil & 1.34 & 0.82 & 0.30 & 0.02 & & & & 2.48 \\
\hline & Tarmats & 1.93 & 7.90 & 4.43 & 0.81 & 0.06 & & & 15.13 \\
\hline & Black Soil & 0.13 & 12.71 & 54.95 & 22.81 & 1.64 & 0.03 & & 92.26 \\
\hline & Cont. Soil & 0.01 & 0.59 & 40.70 & 177.10 & 109.62 & 0.84 & 0.01 & 328.87 \\
\hline & Polluted Soil & & & 1.33 & 25.67 & 167.34 & 44.12 & 0.16 & 238.62 \\
\hline & White Soil & 0.01 & & & 15.85 & 29.97 & 128.56 & 33.15 & 207.54 \\
\hline & Total & 4.35 & 22.24 & 101.74 & 242.26 & 308.62 & 173.55 & 33.33 & 886.09 \\
\hline
\end{tabular}

\section{CONCLUSION}

Remote sensing is highly helpful tool to detect the changes in spatially. The impact analysis of oil pollution in Kuwait has been analyzed using remote sensing techniques. During the study period the study area has been faced more changes due to oil exploration. The oil leakages were affected the vegetation and burned the vegetation as well as the soil characters were contaminated. The oil lakes before Gulf war (1990) was only $0.30 \mathrm{~km}^{2}$ became $27.84 \mathrm{~km}^{2}$ in 1993 reduced into $4.24 \mathrm{~km}^{2}$ in 1999 . In the same way, the oil lakes in 2006 were only $2.95 \mathrm{~km}^{2}$ but it is showing only $1.20 \mathrm{~km}^{2}$ in the change detection (1999-2006) image. The oil lakes of change detection $1993-1999$ of $4.35 \mathrm{~km}^{2}$ became $0.94 \mathrm{~km}^{2}$ in oil lakes, $1.34 \mathrm{~km}^{2}$ in dark oily soil, tarmats $1.93 \mathrm{~km}^{2}$ and black oil $0.13 \mathrm{~km}^{2}$ between $1993 \& 1999$ became oil lakes in $0.94 \mathrm{~km}^{2}$ and $0.22 \mathrm{~km}^{2}$ from 1999 to 2006 . The same way, total areas of Dark oily soil was $22.24 \mathrm{~km}^{2}$ of which $0.22 \mathrm{~km}^{2}$ was oil lakes, tarmats $7.9 \mathrm{~km}^{2}$, black soil $12.71 \mathrm{~km}^{2}$ and $0.59 \mathrm{~km}^{2}$ in contaminated soil.

\section{REFERENCES}

[1] Abdullah, F. and Lalit Kumar (2013). Investigating the use of remote sensing and GISTechniques to detect land use and land cover change, a review. Advancein Remote Sensing, 2: 193-204.

[2] Abou El-Magd, I. and Tanton, T.W. (2003). Improvements in land use mapping for irrigated Agriculture fromsatellite sensor data using a multistage maximum likelihood classification.
International Journal of RemoteSensing, 24: 41974206.

[3] Al-Ajmi, D., Misak,R., Kalaf, F.I., Al-Sudairawi, M. and Al-Dousari, A.M. (1994). Damage Assessment of the desert and coast environment of Kuwait by remote sensing (VT001C). Report No. KISR 4405, Kuwait Institute for Scientific Research, Kuwait.

[4] Aronoff and Stan (1982a). Classification Accuracy: A user Approach. Photogrammetric Engineering \& Remote Senisng, 48(8): 1299-1307.

[5] Cardille, J.A. and Foley, J.A. (2003). Agricultural land-use change in Brazilian Amozoniabetween 1980 and 1995: Evidence from integrated satellite and census data. Remote Sensing of Environment, 87: 551-562.

[6] Chavez, P. S. Jr. (1984). Digital processing techniques for image mapping with Landsat TM and SPOT simulator data. Proc. $18^{\text {th }}$ international symposium on remote sensing of the environment.Paris, $\quad$ France, 1-5 October.Environment Research Institute of Michigan.(pp.101-115).

[7] Chen Xiuwan, HuHeping, Ryutaro Teteishi, ChungHyun Ahn, (1999).A method on land cover classification by combining unsupervised algorithm and training data. GeocartoInternational, 14(4).

[8] Colwell, J.E. and Weber, F.P., 1981, Forest change detection. In Proceedings of the $15^{\text {th }}$ International Symposium on Remote Sensing of Environment (Chelsea, MI: Ann Arbor Press). 
[9] Congalton, R.G. and Green, K. (1999). Assessing the accuracy of remote sensing data:Principles and Practices (Boca Raton, FL: CRC/Lewis Press).

[10] Congalton, R.G. (1991). A review of assessing the accuracy of classification of remotelysensed data. Remote Sensing of Environment, 37, 35-46.

[11]Deng, J.S.,Wang, K., Deng, Y.H., and Qi, G. J. (2008) PCA-based land-used change detection and analysis using multiemporal and multisensory saltellite data. International Journal of Remote Sensing, 29(16) 4823-4838.

[12]Dickison, R., 1995, Land processes in climate models. Remote sensing of Environment, (51)27-38.

[13]El-Baz, F., Abuelgasim, A., Koch, M., Pax-Lenney, M., Lambin, E., Al-Doasari, A., Marr, P,Ryherd, S. andMorency, R. (1994). Detection by satellite images of environment changes due to the Gulf War. In: El-Baz, F. and Makharita, R. M. (eds), The Gulf War and the Environment Gordon and Breach Sci.Publ, Lausanne, pp 1-24.

[14]Eklundh, L. and Singh, A. (1993).A comparative analysis of standardized and unstandardised principal components analysis in remote sensing. International Journal of remote sensing. 14. 13591370.

[15]Foody, G. M. (2002).Status of land cover Classification accuracy assessment. Remote Sensing of Environment, 80, 185-201.

[16]Fung, T. and LeDrew, E. (1987) Application of Principal Components Analysisto Change Detection. Photogrammetric Engineering and Remote Sensing, 53(12), 1649-1658.

[17]Hall, C.A.S., Tian, H., Qi, Y., Pontius, G. and Cornell, J., (1995). Modeling spatialandtemporal patterns of tropical land use change. Journal of Biogeography, 22 73-757.

[18] Howarth, J.P. and Wicware, G.M., 1981, Procedure for Change detection using Landsat digital data. International Journal of Remote Sensing, 2, pp. 277291.

[19]Jackson,B.B., Multivariate data analysis: An Introduction Irwin, Homewood,Illinois, USA, (1983).

[20] Jensen, J.R. (1986). Introduction Digital Image Processing: A remote Sensing Prospective, Englewood Cliffs, New Jersey: Prentice-Hall, 379pp.

[21] Ji, C.Y., Liu, Q.H., Sun, D.F., Wang, S., Lin, P. and Li, X.W., 2001, Monitoring urban expansion with remote sensing in China.International journal of Remote Sensing, 22, pp.1441-1455.

[22] Koch, M. and El-Baz, F. (1998).Identifying the effects of the Gulf War on the geomorphic features of Kuwait by remote sensing and GIS. PE\&RS 64, 7, pp 739-747.

[23] Kwarteng, A. Y. and Al-Ajmi, D., (1997). Satellite remote Sensing Application in the State of Kuwait. A 100pages book published at 1997

[24] Kwarteng, A. Y., (1998). Multitemporal remote sensing data analysis of Kuwait's oil lakes Environment International. Vol. 24, No1/2, pp 121137.

[25] Kwarteng, A.Y. and Chavez, P.S., (1998). Change detection study of Kuwait city and environs using multi-temporal Landsat Thematic Mapper data. International Journal of Remote Sensing.Vol. 19(9), pp. 1651- 1662 .

[26] Kwarteng, A. Y., (1999). Remote Sensing Assessment of oil lakes and oil polluted surface at the Great Burgan oil field, Kuwait. International Journal of Applied Earth Observation andGeoinformation. Vol. 1 (1): pp. 36-47.

[27] Lillesand, Thomas, M. and Ralph Kiefer, M. 1994). Remote Sensing and image Interpretation. John Wiley and Sons, Inc., NewYark, p750.

[28]Lobo, A., Legendre, P., Rebollar, J.L.G., Carreras, J. and Ninot, J.M., (2004). Land cover Classification at a regional scale in Iberia: Separability in a multitemporal and multi-Spectral data set of satellite image.International Journal of Remote Sensing, 25:205-213.

[29]Lu, D., Mausel, P., Brondizio, E. and Moran, e., 2004, Change detection techniques.International Journal of Remote Sensing, 25, pp. 2365-2407

[30] Lunetta,R.S., and Elvidge, C.D., 1998, Remote Sensing Change Detection: Environment Monitoring Methods and Applications (Chelsea, MI: AnnArbor Press).

[31] Musaoglu, N., Coskon, M. and Kocabas, V. (2005). Land use change analysis of Beykoz-Istanbul by mean of Satellite images and GIS. Water Science and Technology, 51: 245-251.

[32] Nelson, R.F., 1983, detecting forest canopy change due to insect activity using Landsat MSS. Photogrammetric Engineering and Remote Sensing, 49, pp. 1303-1314.

[33] Pilon, P.G., Howarth, P.J., and Bullck, R.A., 1988, an enhanced approach to change detectionin semiarid environments. Photogrammetric Engineering and Remote Sensing, 54, pp. 1709-1716.

[34]Robb Macleod, D. and Russell Congaton, G., (1998); Photogrammetric Engineering \&Remote Senisng, 64, No.3; 207-216.

[35] Rogan, J. and Chen, D.M., 2004, Remote sensing technology for mapping and monitoring land-cover and land-use change, Progress in Planning, 61,pp. 301-325. 
[36] Sabins, F.F., 1997, Remote Sensing: Principals and Interpretation, 494pp, (New Yark: W. H.Freeman and Company).

[37] Samira Omar; Gerard Grealish and Waleed Roy, (2006).Types and extent of soilContamination in Great Burgan oil field, Kuwait. Kuwait Journal of Science and engineering.33 (2): 89-99.

[38] Shen, R.P. and Kheoruenromne, I., 2003, Monitoring land use dynamics in ChanthaburiProvince of Thailand using digital remotely sensed images, Pedosphere,(19):157-164.

[39] Singh, A., 1989, Digital change detection techniques using remotely sensed data.International Journal of Remote Sensing, 10, pp. 989-1003.

[40] Story Michael and Russell Congalton, G. (1986). Accuracy Assessment: A User'Perspective, Photogrammetric Engineering \& Remote Senisng. 52(3): 397-399.

[41] Yang, X. and Lo, C.P., 2002, using a time series of satellite imagery to detect land use and land cover changes in the Atlanta, Georgia metropolitan area. International Journal of Remote Sensing, 23, pp. 1775-1798.

[42] Yeh, A.G.O and Li X., 1999, Economic development and agricultural land loss in the PearlRiver Delta, China.Habital International, 23, pp373-390. 